\title{
Analysis of Different Domains of Artificial Intelligence
}

\author{
Seema Gupta ${ }^{\# 1}$, Chandra Prakash Bhatt ${ }^{* 2}$ \\ ${ }^{I}$ Professor, Bhagini Nivedita College, University of Delhi, India \\ ${ }^{2}$ Managing Director, Eco Preneurs Business and Health Management $(P)$ Limited, Gurugram, India
}

\begin{abstract}
Artificial Intelligence (AI) is simply the ability of a Machine to act as "intelligence" as a human. It can be as directly showing human intelligence as identifying picture, understanding voices or observing the real-world problems and come out with a solution intelligently. Machine learning, deep learning, natural language processing, chatbots, disease recognition, playing games, personal assistance etc. are different domains of AI. It can help human to great extent by doing the tasks which human normally does and let the humans free to evolve and involve in new discoveries. It is being said from many different platforms that future lies to those who has command over machine in terms of AI. There is also one thought that AI growth has danger to control the world beyond human power and machines may rule in future. This paper starts with a basic introduction of $\mathrm{AI}$ and then lends us into its scope by talking about its technology domain and its different applications.
\end{abstract}

Keywords - Artificial Intelligence; Data; Machine Learning; Deep Learning.

\section{Introduction}

Artificial Intelligence(AI is much of a buzz word nowa days. Anything that you can think of, done by machine comes under AI. Its giving machine a power to learn from its experiences and improve itself to give better results. It's also about doing the jobs which a human normally does by using its intellect. AI requires good training of the machine given in forms of data and algorithms. AI terms has being coined in the Dartmouth Conference in 1956 as a field of study under Computer Science[1]. Since then it has been in the dreams and reality to realise the potential of AI and make the machines truly intelligence. So many science fictions let to show our imaginations and there has been so much research around it all over the world.

Supporters of AI advocate AI as key to our civilization's bright future whereas those who oppose it gave caution that machines once become intelligent may rule the world and even destroy the humanity as well. No matter you are a supporter or not, you cannot escape AI for now[2]. Some says AI is future, some says its mere science fiction, other says its already into our everyday lives. All these are true depending upon which way and which part of AI one is referring to. Over the past few years the AI growth has been very substantial leading many uses of it. Machines are being made to learn from itself and past data act as training set for this purpose.

New innovations in Semi-conductor chips, storage devices and increased processing power made it possible to see big data analytics as reality. With the advancement of internet speed, now there are lots of data in public domain and for private entities also it is possible to store large amount of data and do processing on it to get requisite results. Data is now available from multiple sources and in multi forms like images, text, transactions, mapping data etc. Many innovators have become entrepreneurs in this emerging field and big companies are investing hugely to be the first to grab its advantages. New jobs have emerged in computer science, mathematics and information technology to give AI its desired boom and get benefitted by its applications.

\section{Key terms in AI}

\subsection{General AI and Specific AI}

AI can be categorised as General AI- super machine which has all the senses as human has and even more like great memory and computing power. It can think, act and react like a human does. Specific AI related to performing some kind of intellect task which are as good as human or even better than human such as playing game, voice assistance, face recognition, pinarest, route locating, driving cars[3].

General AI has so far remained in the science fiction movie or in books of imagination and we directly don't know when will we be able to achieve. Will we achieve after 20 years with current slow progress or we will achieve with next 2-3 years is a big question? As if now, with today's scenario, we don't see fully functional AI machine within next 20 years but history tells us same was predicted with invention of computers and then internet. So, we might see such drastic progress in the field of $\mathrm{AI}$ as well. Google's search engine, Facebook's photo tagging feature, Baidu's speech recognition involves AI. Facebook has invested heavily in AI and getting good results also. Google is also in the war to win the digital bettle. AI field has already started showing great advancements as companies are hugely investing in these field. 


\section{Machine Learning}

It is techniques to get human like intelligence by machine. Machine learning is a field of data science, wherein a machine can learn itself without explicitly handcoding [4]. It's the machine learning on its own from past data, information and present situations rather than somebody explicitly defining the codes to what to do in what scenario. It uses the past data called as "training data", it forms patterns and models which it uses to make different scenarios and make future predictions or reactions in various situations. It uses set of algorithms to understand data and learn from the data and then then make a prediction of a situation or result. In machine learning large amount of data and algorithms are feed to machine as training set. The machine learning precisions and predictions are improving day by day now. Some of the popular Machine learning techniques are Linear Regression, Logistic Regression, Decision Tree, K-Means Clustering, K -Nearest Neighbour, Naïve Bayes Classifier, Random Forest, Artificial Neural Networks, Ensemble Learning [5][6].

\section{Deep Learning}

It is a technique to implement Machine Learning. In deep learning there is no test data and machine itself has to punish or reward for its actions. It is basically inspired from Neural Networks that are found in human body. The way these Neurons carry information and their interconnections with each other leads to passing of information to brain and acting happens similar way deep learning works. Deep learning means neural networks with a large number of hidden layers[6]. So far artificial Neurons are able to connect within layers unlike biological Neurons which can connect to each other within different layers as well. There is also limited connectivity, direction of data and discretization of layers in case of artificial Neurons[7]. Exact working of Deep learning is not much known, just like functioning of human brain is unknown. It many times behave like Blackbox since we know the input and output but the internal working is not much visible. Applications of deep learning includes natural language processing, spam filtering, fraud detection and many more. One of the vital applications of Deep learning is image recognition which is some scenarios even better than humans. Example includes identification of image of cat to indicators of cancer in blood and tumours in MRI scans. Google's AlphaGO is an excellent example of deep learning, which has learned how to play game GO by playing again and again with itself and learning with each game and let learn its Neurons what to do in what situations [2]. Driverless Cars, Preventive Healthcare even movie, serials and songs recommendation, intelligent personal assistance, all are example of deep learning which are giving new horizons to AI [7][8].

\section{Key Milestones in the History of AI}

Table 1: Major milestones in AI History

\begin{tabular}{|c|c|}
\hline $\begin{array}{l}\text { Time- } \\
\text { period }\end{array}$ & Milestone \\
\hline 1950 & $\begin{array}{l}\text { Alen Turing Test. It gave a concept of thinking } \\
\text { in machine if it can talk like human. i.e. if a } \\
\text { machine can carry out a conversation which } \\
\text { cannot be differentiated from that of a human } \\
\text { being. }\end{array}$ \\
\hline 1956 & $\begin{array}{l}\text { In the Dartmouth conference, the } \mathrm{AI} \text { is coined as } \\
\text { a field of computer science. }\end{array}$ \\
\hline 1974-80 & $\begin{array}{l}\text { The period is termed as AI winter since the } \\
\text { funding and government spending in the field of } \\
\text { AI has reduced drastically after several reports } \\
\text { came which criticises the very idea of AI. }\end{array}$ \\
\hline $1980-87$ & $\begin{array}{l}\text { The AI field was again gained popularity with } \\
\text { Japanese efforts and British government } \\
\text { funding. Movie making started on AI with first } \\
\text { popular movie "The Terminator" came in the } \\
\text { said period. }\end{array}$ \\
\hline $1987-93$ & The Second AI winter period \\
\hline 1997 & $\begin{array}{l}\text { IBM's Deep Blue Computer beat the reigning } \\
\text { world champion-Garry Kasparov. AI again } \\
\text { gained popularity. }\end{array}$ \\
\hline 2001 & $\begin{array}{l}\text { Concept of AI again discussed widely after } \\
\text { Steven Spielberg's movie on AI "AI-Artificial } \\
\text { Intelligence" showed a robotic boy who wants to } \\
\text { be human. }\end{array}$ \\
\hline 2011 & $\begin{array}{l}\text { Two major breakthroughs: IBM's Watson wins } \\
\text { an American TV quiz "Jeopardy" defeating } \\
\text { former champions and Apple introduced an } \\
\text { intelligent personal assistant "Siri" on its iPhone } \\
\text { 4s. }\end{array}$ \\
\hline 2012 & $\begin{array}{l}\text { Google launched its version of Siri- "Google } \\
\text { Now". }\end{array}$ \\
\hline 2014 & Amazon Echo was launched. \\
\hline
\end{tabular}

There are various periods of $\mathrm{AI}$ growth and $\mathrm{AI}$ stagnation both in terms of funding and breakthroughs. Since AI was first conceptualized by Alen Turing with "Turing Test" in 1950 and coined in 1956 at Dartmouth conference, it has passed through periods of appreciation with heavy funding to period of cold winter with even researchers criticising it. List of some major milestones in the history of AI is given in the Table 1. Since 2015 it has gained wider recognition as well as acceptance. Many of the tasks have become possible now with AI and many tasks has become easier with AI.

\section{AI as Industry and Governance}

AI Industry has shown unparalleled growth and money as an industry. The governments all over the world acknowledge the power of $\mathrm{AI}$ as a key growth factor for 
their nation's betterment. Governments have all the primary data about public which can be managed and new insights can be obtained using data science and AI. However as in current scenario there is deficit of data in terms of AI industry to use it and understand the public with accuracy and give insight. Problems are also in management of data and digital infrastructure. There is also absence of policy and law to manage data and digital infrastructure. Data is not easily accessible to those who can utilize it. However large private entities are using AI to build themselves as parallel government structures [11]. While the governments are looking for options to explore the AI for public welfare and governance and preparing capacity building for AI, The United Arab Emirates(UAE) has become the first and the only country which has a state minister for AI since 2017, to look for AI with view to become the world's most prepared country for AI[9]. The other countries are seeking for reports on regulations and coordination with industries before actually creating a ministry for it. Japan in 2016 advocated for drafting the basic rules to govern $\mathrm{AI}$, although they are still not enforceable in any county so far. There is also talk about human-centric AI in Group of Seven(G7) in 2017 but no final regulations have been formed so far. In United States of America(USA) there has been several workshops around $\mathrm{AI}$ and public policy including recommendation for Federal Robotics Commission. European Union has adopted digital single market strategy and has appointed a digital commissioner and they are still in the process of collecting feedbacks and information from member nations and industries to draft effective and responsive policy to govern AI. Germany's ministry of research looks after portfolio of $\mathrm{AI}$ and has adopted a strict approach to regulate the social media companies for hate speech. Finland also takes AI very seriously, still the AI portfolio is looked after by ministry of Economic affairs. In Japan's Tama city, an AI actually ran for Mayor's election. There is one thought that if governments will be too slow in understanding and acting on time on AI, AI might become the government. Which means that the private companies which are investing heavily on $\mathrm{AI}$ and making their $\mathrm{AI}$ stronger and stronger may actually control the flow of data, digital management and general public and government may need to depend on them[10][11]. India has also formed a task force under Ministry of Commerce and Industries, for identifying the potential domains for AI. The task force has identified 10 important domains of relevance to India namely Manufacturing, FinTech, Healthcare, Agriculture/Food Processing, Education, Retail, Accessibility Technology, Environment, National Security and Public Utility Services [12].

\section{AI Innovations and Patent Filing}

In this section, we wish to examine the status of AI innovations with patent filing rate in different countries and databases. World Intellectual Property Organization's facilitate international filing named as PCT application with a facility that applicant can enter into national phase of their country of priority within 12 months. Thus, an applicant having an invention of international reach and importance usually go for PCT filing and then they file their patent application in multiple countries. It has a worldwide patent database named a PCT database. On investing the patent database PCT for AI and related invention we found 5437 patents applications with key word "artificial intelligence" as in August 2018. If we further analyse these data we find that 1029 applications have filed USA as priory country while there were no applications seen for India as priority country. This shows that companies are considering USA in big way or companies of USA are much active in AI then in India.

European Patent Office (EPO) worldwide database of patents filed and granted in different European countries and other countries as well. When we analyse the worldwide database of EPO, we found 6307 patent application in the field of artificial intelligence in title or abstract out of which 2107 patent applications has artificial intelligence in its title. The appearance of key word in title tells us that the invention is very much related to the field whereas the key word appearance in the title or abstract imply the inventions are in allied fields. The result also shows that worldwide and in Europe, companies are engaged in AI in substantial way. For country specific databases, we analysed the USA Patent office(USPTO) databases for inventions related to AI. When we searched with keyword AI in the title of invention, we found 359 application from 2001 till August 2018. When keyword is searched in title or abstract, 939 applications are found. One important observation is that USPTO has more than 550 patents granted in this field so far thus the total is far more than the WIPO applications. It means that companies are directly applying and getting patent in USA as well.

Table 2: Granted Patent in India on AI

\begin{tabular}{|l|l|l|}
\hline $\begin{array}{c}\text { Year } \\
\text { of } \\
\text { filing }\end{array}$ & Applicant & \multicolumn{1}{|c|}{ Title } \\
\hline 2005 & $\begin{array}{l}\text { MICROSOFT, } \\
\text { USA }\end{array}$ & $\begin{array}{l}\text { A method for generating an } \\
\text { avatar and a system thereof. }\end{array}$ \\
\hline 2005 & $\begin{array}{l}\text { SIEMENS, } \\
\text { Germany }\end{array}$ & $\begin{array}{l}\text { Device and method for } \\
\text { monitoring a technical facility } \\
\text { comprising multiple systems, in } \\
\text { particular a power plant facility }\end{array}$ \\
\hline 2002 & DRDO, India & $\begin{array}{l}\text { A real time flight monitoring } \\
\text { system }\end{array}$ \\
\hline
\end{tabular}

When we look insight of Indian patent database, we find only 35 applications are published as on August 2018 with AI in its title and 132 applications with AI in its 
abstract. Only 3 patents are granted with these titles so far. These three granted patents are listed in table 2. Year-wise details of number of filing from 2018 till 2001 in the field of $\mathrm{AI}$ is given in table 3 . It must be noted that before 2005 the applications are almost nil.

Table 3: Year-wise published patent applications in India

\begin{tabular}{|c|c|c|c|}
\hline $\begin{array}{c}\text { Year of } \\
\text { filing }\end{array}$ & $\begin{array}{c}\text { Number of } \\
\text { applications }\end{array}$ & Year of filing & $\begin{array}{c}\text { Number of } \\
\text { applications }\end{array}$ \\
\hline 2018 & 6 & 2009 & 0 \\
2017 & 7 & 2008 & 0 \\
2016 & 3 & 2007 & 1 \\
2015 & 1 & 2006 & 0 \\
2014 & 3 & 2005 & 0 \\
2013 & 1 & 2004 & 0 \\
2012 & 8 & 2003 & 0 \\
2011 & 1 & 2002 & 0 \\
2010 & 4 & 2001 & 0 \\
\hline
\end{tabular}

We can see that India has not being very active in AI in terms of patent applications filing and grant. It has less than 10 applications in any year for AI. This data includes both Indian and foreign applications, which further show that the companies presently not considering India for their AI research or AI based products.

\section{Some start-ups in the fields of AI in India}

After analysing the innovations and patent filing and grants in different nations and India, next we move to find some of the start-ups working in different fields using AI. We found a good number of start-ups and entrepreneurs working in various regions of India. We are hereby detailing some of start-ups in the field of AI. Mostly founded in or after 2010 these start-ups have their business model around different applications of AI. For example, Formcet is an AI based data analysis platform that provides companies with actionable insights quickly and affordably. It can be used by decision makers, data Stewards, analysts/scientists. Formcet plate form can be used for both public as well as private cloud. V Phrase is another start-up that provides a platform that describes the data in words and generates insights that help with decision making.Fluid AI is providing solutions using AI for government and private sectors in finance and marketing domain. Their solutions also include a highly accurate facial recognition service. They have many awards and recognition to their name and their work.

CruxIQ started in 2014 is an artificial intelligence startup that helps you analyze legal contracts and extract information to help you keep important clauses at your fingertips. Their features include contract organization, deviation analysis, RAG analysis, while Arya.ai is providing supporting tools for companies who are building intelligent systems.

Active.ai established in 2016 using AI in financial services. They provide a micro-conversational platform with "Predictive and proactive ability to handle "small talk," financial queries and transactions using AI.

AIndra Systems, founded in 2012 is an AI powered Medical Technology company. Their test and results are data driven which is fast in comparison to traditional processes and also customized for patients. They have an AI based platform named "Astra" to detect critical illnesses such as Cancer. Tricog is working in medical field to ease access to diagnosis for heart attack at real time with accuracy and affordability. The doctor can take appropriate actions within minutes and mortality can be reduced. SigTuple builds intelligent screening solutions to aid diagnosis through AI-powered analysis of visual medical data. Their AI platform Manthana has enabled them to work on five major processes of the healthcare industry analysis of peripheral blood smears, urine microscopy, semen, fundus \& OCT scans and chest X-rays.

Artivatic data labs is a start-up started in 2016 with an aim to use AI to make better personalized decisions about their taste, health, lifestyle, fitness, eating, entertainment and physiologic responses, whileHaptik started in 2013 can help set reminders, find the places around you, plan your travel, book a cab, recharge \& pay your bills, web check-in.

Ikenpesonics provides AI based telecom, media and entertainment, travel and insurance, retail and banking through various channels. Morph.ai strated in 2016 provides chatbot to create personalized marketing. Niki.ai started in 2015 is an AI-based personal assistant and India's first fully automated chat bot app with no human intervention which helps you pay the bills,book movie tickets, get cabs and similar other job with directchatting interface online.

Locus.sh started in 2015 uses data driven algorithms to optimize logistics for businesses. Locus.sh solutions include real-time tracking of fleet though an on-field app having dashboard with many insights.

My Ally has developed AI based Human Resource Management which can schedule interviews using machine learning and natural language processing with potential candidates.

Staqu uses artificial intelligence to provide solutions for visual search, automated meta-tag generation, visual recommendation including face recognition, gesture 
recognition, emotion recognition, pose estimation, intruder detection. MAD street Den is Computer Vision \& Artificial Intelligence Company building the AI architecture of the future. Braina AI Assistant started in 2013 which provide a virtual personal assistance and let their voice recognizable with their computer to interact with it from anywhere in the house.

\section{Conclusion}

We have analysed the field of AI from different perspective. The patent data above tells us the seriousness of exploitation of AI in different countries. It also depicts which countries are being looked as positive for multinational companies. When we look insight of Indian patent database, we find only 35 applications are published as on August 2018 with AI in its title and 132 applications with $\mathrm{AI}$ in its abstract. Only 3 patents are granted with these titles so far. Thus India needs to do a lot to facilitate AI innovations in the future.

We also found that the current focus in different countries is presently on research to exploit the power of AI rather than regulations. Governments are still understanding the problems to use of AI by them and their industries. The governments need to act fast before it become too late for them to understand and figure out the potential benefits and harms and device methods to deal with favourable or unfavourable situations. It is very important for government to understand AI's Power and how AI can change the future. AI can benefit or harm depends on the way it will be used. It is like any other technology which is being invented. But the important is to understand it, discuss about it and it should be with large participation of public.

The discussion about start-ups tells us that entrepreneurs have already started their business models around AI and working in all domains using AI. They need to be facilitated and incentivized more to grow up and more to join.
AI is a complex, all-pervasive technology which has many facets. It requires a truly multidisciplinary approach to handle and utilize it for the benefit of mankind. It can help human to great extent by doing the tasks which human normally does and let the humans free to evolve and involve in new discoveries. Future lies to those who has command over machine in terms of AI. AI has lot potential it's up to us how we utilize it. No matter you are a supporter or not, you cannot escape AI for now.

\section{References}

[1] https:// medium.com/ @ montouche / understanding -ai -and -theshades- of -difference -among -its - subsets -4c84b106d0c1

[2] https:// www.telegraph.co.uk/ science/ 2017/ $10 / 18 /$ alphago -zero -google -deepmind -supercomputer -learns-3000 -years/

[3] https :// www. analyticsvidhya. com /blog / 2016/12 / artificialintelligence-demystified/

[4] https://www.quora.com/Machine- learning-is-a-subset-of-AI-whatare-all-the-subsets-of-AI

[5] https:// www.forbes.com/ sites/ tiriasresearch/2017/09/20/machinelearning-the-evolution-from-an-artificial-intelligence-subset-toitsown -domain/\#5f332d37ace2

[6] https:/ / deeplearning4j.org / ai- machinelearning - deeplearning

[7] https:// www.computerworld.com / article / 3040563 / enterpriseapplications/5-things-you-need-to-know-about-ai-cognitive-neuraland-deep-oh-my.html

[8] https :// blogs.nvidia.com / blog / 2016 / 07/29 / whats - differenceartificial-intelligence-machine-learning-deep-learning-ai/

[9] https://futurism.com/uae-minister-artificial-intelligence/

[10] https:// www.cigionline.org /articles/ministry-artificial-intelligence

[11] Cedric Villani, "For a meaningful Artificial Intelligence: Towards a French and European Strategy, A parliamentary mission from 8th September 2017 to 8th March 2018, Available at https://www.aiforhumanity.fr/pdfs/Mission Villani_Report_ENGVF.pdf.

[12] V. Kamakoti, "The Artificial Intelligence Task Force" India, 2018, Available at https://dipp.gov.in/sites/default/files/Report_of_Task_ Force_on_ArtificialIntelligence_20March2018_2.pdf. 